\title{
Compassion Focused Therapy for People with Dementia: A Feasibility
}

\section{Study}

Short running title: CFT for dementia: a feasibility study

Catriona Craig ${ }^{1}$, Syd Hiskey ${ }^{2}$, Lindsay Royan ${ }^{3}$, Rebecca Poz ${ }^{4} \&$ Aimee Spector ${ }^{1}$

Department of Clinical, Educational and Health Psychology, University College London, London, United Kingdom

${ }^{1}$ University College London

${ }^{2}$ Essex Partnership University NHS Foundation Trust

${ }^{3}$ North East London NHS Foundation Trust

${ }^{4}$ Norfolk and Suffolk NHS Foundation Trust

Correspondence to: Dr Catriona Craig, email: catrinacraig@nhs.net

Word count: 3487

Acknowledgements: The authors would like to thank Fiona Patterson, Mary Heatley and Tanisha De Souza for giving their time to the study. 


\section{Compassion Focused Therapy for People with Dementia: A Feasibility}

\section{Study}

Objectives: There is a lack of evidence-based psychological therapies for dementia and psychological distress. The study aimed to develop a Compassion Focused Therapy (CFT) intervention for people with dementia with depression and/or anxiety, and to assess its feasibility, acceptability and utility.

Methods: A mixed methods multiple case-series $(n=7)$ was used to assess the intervention's feasibility and changes in self-compassion, mood, anxiety and quality of life. Outcome measures were administered at pre-intervention, midpoint, and post-intervention. Data were analysed using reliable change and clinically significant change. Thematic analysis on posttherapy interviews and session rating forms was used to assess acceptability and perceived change from the intervention.

Results: Over the course of the intervention, improvements in mood, anxiety and selfcompassion were seen and three of six participants moved out of the clinical depression range. Six participants were able to engage in soothing rhythm breathing, and five in discussion of self-criticism and developing self-compassion. Several participants and their carers described increased self-compassion in response to cognitive decline.

Conclusions: CFT can be adapted to be delivered to people with dementia and low mood, anxiety or other distress. The intervention may improve self-compassion, mood, and anxiety. A larger pilot trial with a comparator group and follow-up is needed to evaluate the intervention's effectiveness for people with dementia.

Keywords: Dementia; Compassion Focused Therapy; CFT; depression; anxiety

Key Points:

- People with dementia and mild-moderate cognitive impairment are likely able to 
engage in a CFT intervention

- CFT may increase self-compassion and improve low mood and anxiety symptoms in people living with dementia

- A pilot trial with a larger sample is recommended

\section{Introduction}

Symptoms of low mood and anxiety are commonly experienced by people with dementia $^{1,2}(\mathrm{PWD})$, especially in the early stages ${ }^{3}$, where there is greater awareness of one's cognitive decline. Whilst a dementia diagnosis can have a significant emotional impact ${ }^{4}$, couples have reported a lack of emotional and psychological support following a diagnosis.

There have been promising developments in psychological interventions for PWD, including adapted Cognitive Behaviour Therapy (CBT), shown to be feasible and effective for those with anxiety ${ }^{5}$. The feasibility and usefulness of third-wave interventions, specifically mindfulness for dementia, are also beginning to be evaluated ${ }^{6}$. The Cochrane Review of psychological treatments for depression and anxiety in dementia and mild cognitive impairment ${ }^{7}$ showed the potential in reducing depression and improving wellbeing in the context of limited research, yet concluded that further well-designed studies, with clearly defined psychological approaches are needed.

Compassion Focused Therapy ${ }^{8}$ (CFT) aims to build self-compassion in the face of self-criticism and shame ${ }^{9}$ and has a developing evidence for its effectiveness among clinical populations. Studies of adapted CFT in acquired brain injury ${ }^{10}$ and intellectual disability ${ }^{11}$ have found that adapted CFT was feasible to deliver in these populations, with reductions in self-criticism and improvements in mood and wellbeing.

There is significant stigma attached to dementia, often leading to feelings of shame and embarrassment ${ }^{12}$, which may contribute to depression and anxiety. CFT could be well- 
placed, as increasing self-compassion may reduce feelings of shame and moderate associated distress with cognitive impairment. Whilst a published case study and audits of group CFT suggest that it can be adapted, is feasible and may improve mood and increase selfcompassion $^{13-15}$, further exploration of CFT in dementia is warranted in order to assess its feasibility and potential utility in this population.

\section{Aim}

To develop a therapeutic intervention based on CFT for PWD with depression and/or anxiety, and to assess its feasibility, acceptability, and utility within this population.

\section{Research questions}

(1) Is CFT feasible and acceptable to PWD in NHS memory services or similar settings?

(2) Does mood and wellbeing improve in PWD following CFT?

\section{Materials and Methods}

\section{Manual development}

The CFT intervention was developed through a literature review and consultation process with PWD, their carers, and psychologists $(n=23)$. The intervention was designed to be delivered to PWD and their carers on an individual basis, over a course of up to 10 one-hour sessions. It is separated into three phases, an approach which has been found to be useful in adapting CBT for dementia ${ }^{16}$, see Table 1 . The manual was designed to provide a framework but enable flexibility to adapt it to individual needs. A 'supportive other' ${ }^{17}$ was encouraged to attend to provide support and to act as an external memory aid for both home practice and returning to concepts covered during the sessions. Table 1 outlines how CFT was adapted. (Table 1 around here) 


\section{Feasibility Study}

Design

A mixed-methods case series was used. Measures were delivered using an interview format with the person with dementia and their carer, if present. A session rating form (SRF) was completed following each session. Post-therapy change interviews were conducted to gain feedback on individual experiences.

\section{Participants}

Participants were eligible for inclusion if they:

(1) Met the Diagnostic and Statistical Manual of Mental Disorders, Fourth Edition ${ }^{18}$ (DSM-

IV) for dementia of any type, as diagnosed by a memory service;

(2) Had mild-moderate cognitive impairment, as rated from the most recent cognitive assessment either on the Montreal Cognitive Assessment ${ }^{19}$ (MoCA); as 10-25, or the Addenbrooke's Cognitive Assessment, Third Edition ${ }^{20}$ (ACE-III); as 88 or below;

(3) Were experiencing symptoms of depression ( $>10$ on the Cornell Scale for depression in dementia $^{21} ;$ CSDD); and/or anxiety ( $\geq 11$ on the Rating Anxiety in Dementia ${ }^{22}$; RAID);

(4) Had capacity to consent to participate;

(5) Were able to communicate in English;

(6) Acknowledged their cognitive difficulties.

Individuals without a carer who was willing to support them during the therapy were still included.

\section{Procedure}

Ethical approval for the design and evaluation of this intervention was obtained from the London Dulwich Research Ethics Committee. Local R\&D approval was obtained in each NHS site. People were recruited from three memory services and one dementia charity organisation. The study was discussed over the phone and information sheets were sent to the 
person with dementia and their carer, if appropriate. For those who agreed to take part written consent was obtained from the person with dementia and a carer. The intervention was delivered to seven individuals by three clinical psychologists and one trainee clinical psychologist, all trained in CFT.

\section{Measures}

Outcomes were administered at three time-points (pre-intervention, mid-point, and postintervention) by an assistant or trainee clinical psychologist, separately to the treating clinician.

Mood. The CSDD is a 19-item scale that measures symptoms of depression. A score above 10 indicates a likely episode of depression. The scale has good reliability and validity. Anxiety. The RAID is an 18-item scale that measure symptoms of anxiety. A score of 11 or over indicates clinical anxiety. It has good inter-rater and test-retest reliability and is sensitive to change.

Quality of life. The Quality of Life-Alzheimer's Disease ${ }^{23}$ (QOL-AD) is a 13-item measure assessing perceived quality of life. Higher scores indicate a higher quality of life. Inter-rater reliability and internal consistency are excellent and content and construct validity are good. Self-compassion. The Short Self-Compassion Scale ${ }^{24}$ (SCS-SF) is a 12-item scale measuring self-compassion. A score of 3.5 or over is considered high self-compassion; a score of 2.5 or lower is considered low. It has good inter-rater reliability, factorial and convergent validity. Experience of Session. The person with dementia was asked to complete the SRF, rating how helpful they found the session, using a Likert scale. They were also asked what they liked and did not like about the session.

Experience of therapy. Participants' experience of the intervention was explored through a semi-structured interview, which was designed for the study and based upon Elliot, Slatick and Urman's ${ }^{25}$ change interview. 
Analysis

Attendance and SRF data were analysed to evaluate feasibility and acceptability of the intervention. The Reliable Change Index ${ }^{26}$ (RCI) was calculated for each measure that reported reliability coefficients (CSDD, RAID, QOL-AD, SCS-SF). Morley and Dowzer' ${ }^{27}$ reliable change indicator was used to calculate significant improvement, no change, or deterioration over the intervention. Clinically significant change was calculated using either the measure's clinical cut-off (CSDD, RAID) or the clinical and non-clinical sample means and standard deviations (SCS-SF) to determine whether or not post-intervention scores reduced to sub-clinical ranges.

\section{Experience of $C F T$}

Qualitative data were captured through two questions on the SRF and post-therapy change interviews. Five participants were interviewed (four joined by their supportive others) and one supportive other was interviewed separately as the participant's cognition had deteriorated. Interviews were evaluated using thematic analysis ${ }^{28}$.

\section{Results}

Six of the seven participants were female and one was male. Ages ranged from 53 to 88 . Six had supportive others who attended the sessions and facilitated home practice. Table 2 outlines demographic data.

(Table 2 around here)

\section{Feasibility and acceptability}

Five participants completed ten sessions of the intervention. Two completed eight sessions, one due to time constraints of the project. One participant died; their partner provided consent to use their data. 
SRFs were completed for 48 out of $66(73 \%)$ sessions. They indicated that participants found the sessions useful. None rated any sessions as unhelpful. Overall session feedback was positive. See Table 3.

(Table 3 around here)

\section{Intervention coverage}

Although five participants attended all ten sessions, none completed the intervention in the allocated time. Clinicians reported that most participants managed phase one and two (setting up CFT and engagement, developing compassion for the self). Six participants were able to engage in soothing rhythm breathing, and five were able to engage in discussion of selfcriticism and developing kindness and self-compassion. Phase three (managing difficult emotions), was not fully covered, due to the need to spend more time on earlier phases and discussion of the impact of living with dementia.

\section{Mood and wellbeing}

Table 4 shows changes across the intervention time points on outcome measures. Six participants scored in the clinical range for depression at baseline. Five saw a decrease in depression scores across the intervention, with three moving from the clinical to the subclinical range. All scored in the clinical range for anxiety prior to CFT and saw a reduction of anxiety symptoms post-treatment, however only two moved to the sub-clinical range. No participant met a reduction of clinical significance. Two saw a reliable change in anxiety, which required a drop of 10.17 points.

Little change was seen on the QOL-AD. At baseline, six participants scored in the low or moderate self-compassion range. All participants' scores improved on the SCS-SF, and except participant five, all completed the intervention in the moderate or high self-compassion range.

(Table 4 around here) 


\section{Post-therapy interviews}

Thematic analysis generated four superordinate themes, which contained several sub-themes

(Table 5). Participants are referred to by numbers to demonstrate that findings are grounded in a variety of perspectives, for example P1, P2 (participant 1, 2), and SO1, SO2 (supportive other 1,2).

(Table 5 near here)

\section{Theme 1. Support when I needed it}

Participants found CFT helpful, valuing the space to talk to someone who was supportive, compassionate and knowledgeable about dementia.

I: Was there anything else about your sessions with (therapist) that you enjoyed?

P1: Just being able to talk to her

P6: I did get lots of support from (therapist)...he'd ask me how I was last week and how I was this week...he basically opened me up, and gave me time to talk about my week, and problems and things...

Dementia knowledge and skills. Participants and their supportive others valued the therapy being relevant to dementia, with a therapist who could answer dementia-specific questions.

P6: ... having (therapist) there... who was knowledgeable about the condition ... where I could ask him questions... where if we had just a facilitator that didn't know the condition...

A positive experience. Participants described attending the therapy as useful and worthwhile.

P1: I think it has helped me quite a bit yeah. 
Two supportive others, who expressed that they had not seen any changes in their loved ones, still described the experience as a helpful one.

SO2: ....all in all it's been a good experience, I'm very happy with it.

I: What else have you found helpful?

SO4: Having the sessions with ma - that was quite sweet because we've never done something like that together before, so that was quite special. And in a way, it was like having quality time with my mum.

\section{Theme 2. Changes in self and other relating}

Many of the PWD were able to engage in specific compassion practices, which led to considerable emotional changes. The sub-themes describe changes in self-relating, including finding ways to regulate threat-based feelings, and increasing the activation of the soothing system. Some participants also spoke of increased awareness of their own patterns of relating to self and others, and of finding acceptance.

I am calmer. Several participants expressed feeling more relaxed and able to manage feelings of anger and anxiety.

I: ...you said earlier that if something annoyed you, you used to get really angry, has that changed now since the therapy?

P1: Yes, and no. Because I still get like it but I try and control it a bit...I go like this sometimes (breathes in deeply) like you know as if I'm hugging somebody.

I: So since your sessions with (therapist) do you find you're doing anything differently in your day-today life?

P3: Yes I'm trying to relax more, and to take one day at a time... if you ask me what I'm doing tomorrow I can't remember - it doesn't matter - I'll look it up in the morning when I get up and see what I'm doing tomorrow...so I'm more relaxed I think 
P7: I'm calmer than I was...I don't rant and rave and get angry so much

I am kinder to myself. Participants described having more self-compassion and changed how they respond to themselves in relation to their memory problems.

P3: Well I'm more... 'it doesn't matter', more forgiving. 'Well what of it! You've forgotten something'

I: ...So you're nicer to yourself now?

P7: Well I don't shout at me anymore

One participant expressed that he had become more assertive.

P6: But by doing this therapy, and talking to (therapist), I realised...wait a minute I'm not being selfish, I need this time for me, and basically doing this therapy gave me permission to say...uhm... sorry I can't do it.

A supportive other expressed that she was criticising herself less.

SO4: I think I remind myself now...that I'm actually doing a good job. Looking after my mum and everything else I'm dealing with..... and sometimes I forget and I take a step back and I think 'damn, you've been through a lot'. So cut yourself some slack...

Awareness and acceptance. Several participants spoke of noticing themselves and their needs more, as well as accepting themselves and the effects of the dementia.

P7: I have accepted the fact that I have a 'memory problem' and I am happy being me. I also don't blame myself anymore for something that's not my fault.

A supportive other powerfully described his wife's journey from anger and denial of the dementia, to part-acceptance. 
S07: Well the main thing is you've gone from total denial, anger, self-blame...to uh some

acceptance...not complete acceptance

P7: No way...put up with it

SO7: But self-blame...there's still some of that, but...in general the change is total. It wouldn't have happened without the therapy

P7: No, oh no.

Theme 3. Barriers to developing compassion

Even with the significant changes that participants had made a number of challenges in developing compassion were identified.

Memory and cognition. Aspects of dementia may have made it difficult for participants to engage with and process the material, as well as to hold on to the information and experience.

I: ... are there any other specific ideas you've gotten from therapy that have helped you learn different things about yourself, or certain strategies that have helped you in any way?

P3: There was something, but guess what? I can't remember what it was!...I gotta think about it...um <pause> no it won't come like that.

Fears and blocks. Some participants spoke of the difficulty in being kind to themselves.

I: And how are you feeling in yourself that you've developed this more assertive (name)

P6: Still feel guilty!

Themes 4: Something more needed

There was a general sense that even though participants had experienced the CFT as useful, there was a wish for more support.

I do not feel different. Two participants described no change since the therapy. 
I: So you've not taken up anything differently that you weren't doing before or you're not reacting to things differently or?

SO2: No

I: Are you responding to yourself differently in any way?

P2: No

I: What about to other people? Or do you feel the same?

SO2: I would say so.

More support. Some of the participants had suggestions of what could be added to the therapy. In particular, one expressed wanting more help with memory loss and further sessions.

P6: ... this has been brilliant, but I would like to know a bit more about memory training...

P6: Yeah personally I would have liked more.... I found it a big void afterwards.

\section{Discussion}

The results indicate that CFT might have a positive effect on mood, anxiety and selfcompassion in people with mild-moderate dementia. Changes were seen in participants' mood, with six out of seven improving, four reliably so. All saw a reduction in anxiety, although only two saw reliable improvement. All participants experienced an increase in selfcompassion, some considerably so, with four out of six seeing both reliable and clinically significant improvements. Three participants completed the intervention with 'high' selfcompassion, with scores of 4.5-4.6 out of a possible 5. These are considerably higher than the mean of an adult community sample $(M=3, S D=.76)$, and of a sample of meditators ${ }^{29}$ $(\mathrm{M}=3.66, \mathrm{SD}=.61)$. No change was seen in quality of life. 
CFT was acceptable to people with dementia, however the study's intervention manual is not feasible. No adverse events were identified. The sessions were well attended, with five participants completing all 10. Much of the session feedback was related to core components of psychological therapy, including having felt heard and valued a space to talk about the dementia and its impact. Participants also appreciated the compassion-specific aspects, such as developing self-kindness and self-soothing.

Six participants engaged in basic compassion practices, including soothing rhythm breathing, and flows of compassion. Most were also able to discuss concepts related to compassion, such as 'threat' and 'self-soothing'. These findings are consistent with Poz's ${ }^{13-14}$ and Collins, Gilligan and Poz's ${ }^{15}$ initial reports of using CFT in PWD, and the success of adapting CFT for populations with cognitive impairments ${ }^{10,11}$.

\section{Implications for practice and research}

CFT might improve mood and anxiety and may be particularly relevant in this client group, as a diagnosis of dementia and its associated neurological impairments can leave individuals vulnerable to feelings of shame ${ }^{12}$, and experiencing a sense of 'existential threat' ${ }^{14}$.

The flexibility of the manual allowed for adapting CFT to the person's cognitive ability and 'openness' to compassion, however the study found it could not be sufficiently covered in 10 sessions. A systematic review of CFT across clinical populations ${ }^{30}$ indicates that at least 12 hours of CFT is required for an effect. A proposed intervention outline to address these issues can be found in Table 6. It is extended to 12 sessions, with optional sessional content and practices so that clinicians can tailor the intervention based upon their formulation.

(Table 6 near here)

Given that the project was a feasibility study it was not the intention to generalise findings to the wider clinical context at this point. However, in the absence of definitive 
evidence of what kind of psychological therapy works in this client group ${ }^{7}$, the current study suggests that CFT could be a feasible choice for psychologists in NHS memory services.

Once the manual is deemed feasible a trial with a larger sample is needed so that effectiveness can be evaluated using inferential statistics, as well as effect size and the power of any effect. Whilst striking a balance with flexibility of the manual, therapist fidelity to CFT should be measured to prevent therapeutic drift. It would be useful to compare CFT to a wait-list control group, as well as another psychological intervention for people with dementia, such as CBT.

Further research should also aim to understand the process of change of CFT in this population. The thematic analysis indicates that becoming more self-compassionate and talking to a concerned other about dementia were both important. Therefore, it would be useful to identify whether increases in self-compassion are related to a reduction of mood and anxiety symptoms in order to identify the active ingredient/s of change.

Most research into CFT evaluates the effectiveness of group interventions. Not only are group interventions more cost-effective, but the experience of sharing affiliative experiences can be powerfully de-shaming ${ }^{11}$. It would be useful to determine, therefore, how feasible and effective group CFT is for PWD.

\section{Limitations}

The study's findings are limited by the small sample size and no follow-up data, both of which make it difficult to draw conclusions about the impact of the intervention. The SCS-SF is not validated for use with PWD. At least one participant was unable to understand the measure, so it was excluded for this individual. One participant did not have a supportive other, which meant the CSDD, the RAID, and the QOL-AD were completed by the person with dementia only. These measures are validated when completed by a carer, which questions the validity of one participant's scores. 
Even though the manual was designed to be individually adapted, the intervention was changed considerably for two participants. It was delivered to one supportive other due to a lack of understanding from the person with dementia, and the compassion practices were removed for another couple. This does suggest that CFT may be less suitable or helpful for individuals who are more cognitively impaired. Limited data was collected from supportive others; given the importance that carers play in this population further research could measure any impact upon supportive others and gather feedback on their experience.

Participants spoke of challenges that may have inhibited engaging with - and making use of - CFT. For example, not being able to remember what was helpful, and not feeling differently when asked. It is possible that gains can still be achieved in improving selfkindness even if the individual is unable to recall the content of the sessions.

\section{Conclusions}

CFT can be adapted to be delivered to people with dementia who are suffering from low mood or anxiety. The intervention was mostly well liked, and improvements were seen on measures of mood, anxiety and self-compassion. This indicates that people in the mildmoderate stages of dementia can develop self-compassion skills, which may be protective as they continue to navigate progressive cognitive decline. A larger pilot trial with a comparator group and follow-up is now needed before firm conclusions can be made on the intervention's effectiveness for PWD. 


\section{References}

1. Badrakalimuthu V, Tarbuck A. Anxiety: a hidden element in dementia. Adv Psychiatr Treat. 2012;18:119-128, doi: 10.1192/apt.bp.110.008458

2. Enache D, Winblad B, Aarsland D. Depression in dementia: epidemiology, mechanisms, and treatment. Curr Opin Psychiatry. 2011;24:461-72, doi:

10.1097/YCO.0b013e32834bb9d4

3. Lopez O, Becker J, Sweet R, Klunk W, Kaufer D, Saxton J, Habeych M, DeKosky S. Psychiatric symptoms vary with the severity of dementia in probable Alzheimer's disease. J Neuropsychiatry Clin Neurosci. 2003;15:346-53, doi: 10.1176/appi.neuropsych.15.3.346

4. Aminzadeh F, Byszewski A, Molnar F, Eisener M. Emotional impact of dementia diagnosis: Exploring persons with dementia and caregivers' perspectives. Aging Ment Health. 2007;11:281-290, doi:10.1080/13607860600963695

5. Spector A, Charlesworth G, King M, Hoe J, Lattimer M, Sadek S, Marston L, Rehill A, Qazi A, Knapp M, Orrell M. Cognitive Behavioural Therapy (CBT) for anxiety in dementia: A pilot randomised control trial. Br J Psychiatry. 2015;206:1-8, doi: 10.1192/bjp.bp.113.140087

6. Churcher-Clarke A, Chan JMY, Stott J, Royan L, Spector A. An adapted mindfulness intervention for people with dementia in care homes: feasibility pilot study. Int J Geriatr Psychiatry. 2017;doi:10.1002/gps.4669

7. Orgeta V, Qazi A, Spector A, Orrell M. Psychological treatments for depression and anxiety in dementia and mild cognitive impairment (Review). Cochrane Database Syst Rev. 2014;2014(1), doi: 10.1192/bjp.bp.114.148130

8. Gilbert P. An introduction to compassion focused therapy in cognitive behavior therapy. Int J Cogn Ther. 2010;3(2):97-112, doi: 10.1521/ijct.2010.3.2.97 
9. Gilbert P. The Origins and Nature of Compassion Focused Therapy. Br J Clin Psychol. 2014;53:6-41, doi: 10.1111/bjc.12043

10. Ashworth F, Clarke A, Jones L, Jennings C, Longworth C. An exploration of compassion focused therapy following acquired brain injury. Psychol Psychother T. 2015;88:143-162, doi:10.1111/papt.12037

11. Clapton N, Williams J, Griffith G, Jones R. 'Finding the person you really are... on the inside': Compassion focused therapy for adults with intellectual disabilities. J Intellect Disabil. 2017; doi: 10.1177/1744629516688581

12. Cheston R. Shame and avoidance: Issues of remembering and forgetting with people with dementia. Context: the Magazine for Family Therapy and Systemic Practice. 2005;77:1922

13. Poz R. Delivering Compassion Focused Therapy to Couples experiencing a diagnosis of dementia in a group setting: is it feasible? Alzheimer's Europe Conference 2014. 2014a

14. Poz R. Facing degeneration with compassion on your side: Using compassion focused therapy with people with a diagnosis of dementia. Neuro-Disabil Psychother. 2014b;2:82101

15. Collins R, Gilligan L, Poz R. The evaluation of a compassion focused therapy group for couples experiencing a dementia diagnosis. Clin Gerontol. 2017; doi: http://dx.doi.org/10.1080/07317115.2017.1397830

16. Spector A, Orrell M, Lattimer M, Hoe J, King M, Harwood K, Qazi A, Charlesworth G. Cogntive Behavioural Therapy (CBT) for anxiety in people with dementia: study protocol for a randomised control trial. Trials. 2012;13:197, doi: 10.1186/1745-6215-13-197

17. Charlesworth G, Sadek S, Schepers A, Spector A. Cognitive behaviour therapy for anxiety in people with dementia: a clinician guideline for a person-centred approach. Behav Modif. 2014;1-23, doi: 10.1177/0145445514561317 
18. American Psychiatric Association. DSM-IV, 1994. Washington, DC: Author

19. Nasreddine Z, Phillips N, Bedirian V, Charbonneau S, Whitehead V, Collin I, Cummings

J, Chertkow H. The Montreal Cognitive Assessment, MoCA: a brief screening tool for mild cognitive impairment. J Am Geriatri Soc. 2005; 53(4):695-699, doi: 10.1111/j.15325415.2005.53221.x

20. Hsieh S, Schubert S, Hoon C, Mioshi E, Hodges J. Validation of the Addenbrooke's Cognitive Examination III in Frontotemporal Dementia and Alzheimer's Disease. Dement Geriatri Cogn Dis. 2013;36:242-259, doi: 10.1159/000351671

21. Alexopoulos G, Abrams R, Young R, Shamoian C. Cornell scale for depression in dementia. Biol Psychiatry. 1988;23:271-284, doi: org/10.1016/0006-3223(88)90038-8

22. Shankar K, Walker M, Frost D, Orrell M. The development of a valid and reliable scale for rating anxiety in dementia (RAID). Aging Ment Health. 1999;3:39-49, doi: $10.1080 / 13607869956424$

23. Logsdon R, Gibbons L, McCurry S, Teri L. Quality of life in Alzheimer's disease: patient and caregiver reports. J Mental Health Aging. 1999;5, 21-32

24. Raes F, Pommier E, Neff K, Van Gucht D. Construction and factorial validation of a short form of the Self-Compassion Scale. Clin Psychol Psychother. 2011;18, 250-255. doi: 10.1002/cpp.702

25. Elliott R. Slatick E. Urman M. (2001). Qualitative Change Process Research on Psychotherapy: Alternative Strategies. In J Frommer, DL Rennie, eds. Qualitative psychotherapy research: Methods and methodology Lengerich, Germany: Pabst Science; 2001:69-111

26. Jacobson N. Truax P. Clinical significance: a statistical approach to defining meaningful change in psychotherapy research. J Consult Clin Psychol. 1991;59:12-9. doi: 10.1037/0022-006X.59.1.12 
27. Morley S, Dowzer C. Manual for the Leeds reliable change indicator: simple excel applications for the analysis of individual and group data. University of Leeds, Leeds, $\mathrm{UK} ; 2014$

28. Braun V, Clarke V. Using Thematic Analysis in Psychology. Qual Res Psychol. 2006;3:77-101. doi: 10.1191/1478088706qp063oa

29. Neff K, Whittaker T, Karl A. Examining the factor structure of the Self-Compassion Scale in four distinct populations: Is the use of a total scale score justified? J Pers Assess. 2017. doi: $10.1080 / 00223891.2016 .1269334$

30. Craig C, Hiskey S, Spector A. Compassion Focused Therapy: a systematic review of its effectiveness and acceptability in clinical populations. Manuscript submitted for publication. 2018. 
Table 1. Phases of the CFT Intervention and Adaptations.

\begin{tabular}{|c|c|c|}
\hline Phase & Topic & Content \\
\hline $\begin{array}{l}\text { Phase } 1 \\
\text { (Sessions 1-3) }\end{array}$ & $\begin{array}{l}\text { Setting up: Introducing } \\
\text { compassion focused } \\
\text { therapy and engagement }\end{array}$ & 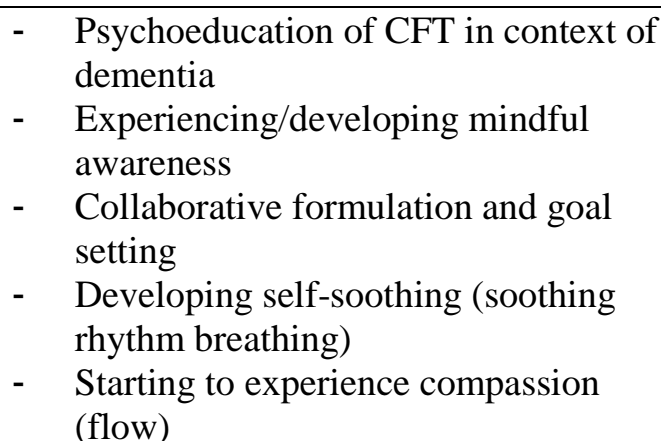 \\
\hline Phase 2 & Developing compassion & $\begin{array}{l}\text { - } \quad \text { Loving-kindness for the self } \\
\text { - } \quad \text { Fears and blocks to compassion }\end{array}$ \\
\hline (Sessions 4-7) & for the self & $\begin{array}{ll}\text { - } & \text { Imagery: safe-place, compassionate } \\
& \text { self } \\
\text { - } & \text { Compassion in everyday life } \\
\text { - } & \text { Compassionate letter/postcard }\end{array}$ \\
\hline Phase 3 & Managing difficult & $\begin{array}{ll}\text { - } & \text { Threat-based emotions } \\
\text { - } & \text { Soften, soothe, allow }\end{array}$ \\
\hline (sessions 8-10) & feelings & $\begin{array}{l}\text { - Returning to key concepts/reflection } \\
\text { on practices } \\
\text { - Reviewing the therapy and } \\
\text { compassionate future }\end{array}$ \\
\hline
\end{tabular}

\section{CFT Adaptations}

Possible

challenges or

problems for the

person with

dementia

\section{Memory}

Including short-term memory loss, difficulties

in new learning, working memory, encoding, and retrieval deficits

Concentration

Attention

Language

Problem solving

Motivation
- Use of supportive other

- CFT psychoeducation grounded in dementia (i.e. even trickier brain)

- Slow delivery of concepts

- Regularly check understanding (after each novel concept)

- Repeat main therapeutic concepts frequently

- Provide regular summaries (every 1015 mins)

- Meditations/practices shortened, less silence

- Provide written summary of the session

- Provide visual hand-outs

- Provide CDs/audio recordings of meditations/home practices

- Consider whether concepts from the previous session/s need to be returned to and prioritise these over introducing new concepts

- Generate flashcards for client's chosen methods of coping/practices 
Table 2. Participant demographics

\begin{tabular}{|c|c|c|c|c|c|c|}
\hline Participant & Dementia & Age & Gender & $\begin{array}{c}\text { Cognitive } \\
\text { Impairment }\end{array}$ & Ethnicity & $\begin{array}{c}\text { Supportive } \\
\text { Other }\end{array}$ \\
\hline 1 & $\begin{array}{c}\text { Mixed AD \& } \\
\text { Vascular }\end{array}$ & 76 & Female & $\begin{array}{c}\text { Mild- } \\
\text { Moderate }\end{array}$ & White, British & None \\
\hline 2 & $\begin{array}{c}\text { Alzheimer's } \\
\text { Disease }\end{array}$ & 83 & Female & Moderate & White, British & Husband \\
\hline 3 & $\begin{array}{c}\text { Alzheimer's } \\
\text { Disease }\end{array}$ & 80 & Female & $\begin{array}{c}\text { Mild- } \\
\text { Moderate }\end{array}$ & White, British & Friend \\
\hline 4 & $\begin{array}{c}\text { Alzheimer's } \\
\text { Disease }\end{array}$ & 83 & Female & Moderate & Black, African & Daughter \\
\hline 5 & $\begin{array}{c}\text { Alzheimer's } \\
\text { Disease }\end{array}$ & 88 & Female & Moderate & White, British & Husband \\
\hline 6 & Vascular & 53 & Male & Mild & White, British & Partner \\
\hline 7 & $\begin{array}{c}\text { Alzheimer's } \\
\text { Disease }\end{array}$ & 73 & Female & $\begin{array}{c}\text { Mild- } \\
\text { moderate }\end{array}$ & White, European & Husband \\
\hline
\end{tabular}


Table 3. Session helpfulness ratings and participant rating form feedback

\begin{tabular}{lllll}
\hline $\begin{array}{l}\text { Extremely } \\
\text { unhelpful }\end{array}$ & $\begin{array}{l}\text { Somewhat } \\
\text { unhelpful }\end{array}$ & $\begin{array}{l}\text { Neither helpful nor } \\
\text { unhelpful }\end{array}$ & Somewhat helpful & Extremely helpful \\
$0 \%$ & $0 \%$ & $1.9 \%$ & $28.8 \%$ & $69.2 \%$
\end{tabular}

Key Themes

1. Feeling heard and helped

2. Enjoyment of the breathing practices

3. Valued space for conversation

4. Sessions as personal to me

5. Developing self-compassion
Participant Feedback

P1: 'I like that you are trying to help me'

P6: '<Therapist> was very helpful and listened to what I had to say'

P1: 'I like the breathing'

P3: 'The breathing helped me to relax'

P6: 'I really enjoyed the mindfulness and relaxation exercises'

SO2: 'I always enjoy the conversation, interesting conversations'

P1: 'Talking about the frustration'

SO4: 'I found it helpful to talk - to release everything and getting things off my chest'

P6: '<Therapist> listening to me and my girlfriend and fitting the sessions around our experiences'

P3: 'Personalised practice'

SO4: 'Thinking of ways of being kind to myself and different ways of helping ma'; 'Being reminded of needing to take care of myself in order to look after mum'

P1: 'You telling me about compassion and the brain'; 'I liked the hand on heart practice'

P6: 'Being told it's ok to be kind to myself'

* Comments from participants with dementia are denoted as P1, P2 etc. (i.e. participant 1, 2). The supportive others' comments are denoted as $\mathrm{SO} 1, \mathrm{SO} 2$ etc. (i.e. supportive other of participant 1,2). 
Table 4. Pre-post raw scores, reliable change and clinically significant change

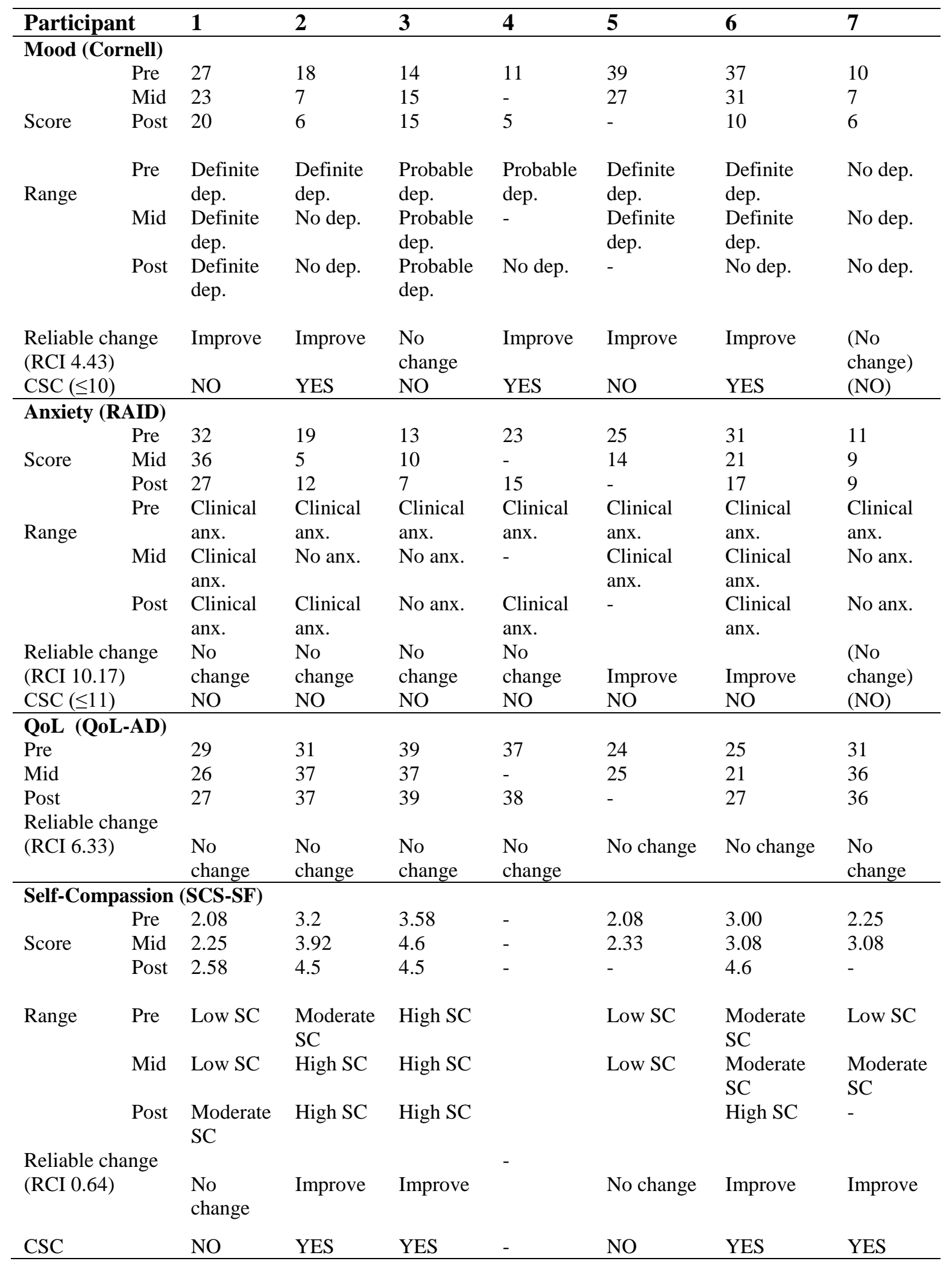

Pre - baseline assessment; Mid - mid-point assessment; Post - post-intervention assessment; dep. - depression; anx. - anxiety; CSC - clinically significant improvement; QoL - quality of life; SC - self-compassion; ‘_‘ denotes missing data

Scores in brackets indicate that the participant scored below the clinical cut off at baseline, so were not able to further improve 
Table 5. Post-therapy interview themes

\begin{tabular}{lll}
\hline \multicolumn{1}{c}{ Superordinate Themes } & \multicolumn{1}{c}{ Sub-Themes } \\
\hline 1. Support When I Needed it & - Someone to talk to \\
& - Dementia knowledge and skills \\
& - A positive experience \\
\hline 2. Changes in self and other relating & - I am calmer \\
& - I am kinder to myself \\
& - Awareness and acceptance \\
\hline 3. Barriers to Developing Compassion & - & Memory and cognition \\
\hline 4. Something More Needed & - & Fears and blocks \\
& - & I do not feel different \\
\end{tabular}




\begin{tabular}{|c|c|c|}
\hline Phase & Topic & Content \\
\hline $\begin{array}{l}\text { Phase } 1 \\
\text { (Sessions 1-4) }\end{array}$ & $\begin{array}{l}\text { Setting up: Introducing } \\
\text { compassion focused } \\
\text { therapy and engagement }\end{array}$ & $\begin{array}{ll}- & \text { Psychoeducation } \\
- & \text { Experiencing/developing } \\
\text { mindful awareness } \\
\text { - } & \text { Collaborative formulation and } \\
& \text { goal setting } \\
- & \text { Developing self-soothing } \\
\text { (soothing rhythm breathing) } \\
-\quad & \text { Starting to experience } \\
\text { compassion (flow) }\end{array}$ \\
\hline $\begin{array}{l}\text { Phase } 2 \\
\text { (Sessions 5-8) }\end{array}$ & $\begin{array}{l}\text { Developing compassion } \\
\text { for the self }\end{array}$ & $\begin{array}{l}\text { Choice of content/practices: } \\
\text { - } \quad \text { Loving-kindness for the self } \\
\text { - } \quad \text { Fears and blocks to compassion } \\
\text { - } \quad \text { Imagery: safe-place, } \\
\text { compassionate self } \\
\text { - } \quad \text { Compassion in everyday life } \\
\text { - }\end{array}$ \\
\hline \multirow[t]{2}{*}{$\begin{array}{l}\text { Phase } 3 \\
\text { (sessions 9-12) }\end{array}$} & Managing difficult feelings & $\begin{array}{ll} & \text { Choice of content/practices: } \\
\text { - } & \text { Threat-based emotions } \\
\text { - } & \text { Soften, soothe, allow }\end{array}$ \\
\hline & Consolidating \& ending & $\begin{array}{l}\text { - } \text { Returning to key } \\
\text { concepts/reflection on practices } \\
\text { - } \\
\text { Reviewing the therapy and } \\
\text { compassionate future }\end{array}$ \\
\hline
\end{tabular}


